Human Parvovirus B19 Infection Among Blood Donors in North-East

\title{
of Iran
}

\author{
Ameneh Karimnia ${ }^{1}$, Ameneh Elikaei ${ }^{1,{ }^{*}}$ and Zohreh Sharifi ${ }^{2,{ }^{* *}}$ \\ ${ }^{1}$ Department of Microbiology, Faculty of Biolgical Science, Alzahra University, Tehran, Iran \\ ${ }^{2}$ Department of Blood Transfusion Research Center, High Institute for Research and Education in Transfusion Medicine, Tehran, Iran \\ "Corresponding author: Department of Microbiology, Faculty of Biolgical Science, Alzahra University, Tehran, Iran. Email: a.elikaei@gmail.com \\ Corresponding author: Department of Blood Transfusion Research Center, High Institute for Research and Education in Transfusion Medicine, Tehran, Iran. Email: \\ z.sharifi@ibto.ir
}

Received 2019 September 08; Revised 2020 August 16; Accepted 2020 August 22.

\begin{abstract}
Background: Human parvovirus B19 is a single-stranded DNA and non-enveloped virus which belongs to the Parvoviridae family. The virus spreads through respiratory secretions and perinatal blood. B19 may cause serious complications in patients with cellular immunodeficiency that have no detectable antibodies to B19, such as aplastic crises in solid organs.

Objectives: The present study aimed to investigate the prevalence of parvovirus B19 and to evaluate the presence of B19 DNA among blood donors in Golestan Province.

Methods: Sera of 400 blood donors in Golestan Province who were negative for HIV, HbsAg, and HCV were tested for both IgG and IgM anti-B19 virus antibodies using the ELISA method, following which all sera were tested for the presence of B19 DNA by semi-nested PCR.

Results: 242 (out of 400 ) subjects (60.5\%; 95\% CI) were positive for anti-B19 IgG, and 158 were negative for IgG antibody (39.5\%; $95 \%$ CI). Moreover, all asymptomatic blood donors were negative for anti-B19 IgM. No viral genome was found in serum samples of donors. Conclusions: Since no viral genome was found in the donors' serum samples and the relatively high prevalence of anti HPV- B19 IgG in blood donors, it can be concluded that the possibility of B19 transmission through blood transfusion is low. However, special caution should be taken when transfusing blood to the high-risk groups such as pregnant women, immune-deficient patients, and those with hematological problems, particularly regarding IgG anti- HPV- B19 antibodies (HPV- B19-safe).
\end{abstract}

Keywords: Blood Donors, Parvovirus, Golestan Province, ELISA, PCR

\section{Background}

Human ParvoVirus B19 (HPV- B19) was discovered by Yvonne Cossart in 1975 (1). B19 is the only member of the Parvoviridae family known to be pathogenic in humans (2). Parvovirus B19 is a non-enveloped capsid small virus with a diameter of 22 to $24 \mathrm{~nm}$. The HPV- B19 is a linear, singlestrand DNA genome that encodes two structural proteins (VP1 and VP2) and a nonstructural protein NS1 (3, 4). HPVB19 is widespread and causes a wide spectrum of clinical disorders, which varies based on the hematological and immunological status of the infected individuals. HPVB19 only causes infection in humans, the most common of which are fifth disease, a common illness in children, chronic pure red cell aplasia, transient aplastic crisis, and prolonged joint pain in elderly individuals, hydrops fetalis, and fetal death $(2,5)$.

Due to the possible presence of B19 in blood or plasma products, it can be transmitted through blood transfusion, which results in severe illnesses (6). HPV- B19 viremia occurs during the first week of exposure to infection and usu- ally lasts for 5 days, with virus titers peaking at 48 hours (7). Specific Anti B19 IgG antibodies can be detected about 15 days after infection, remain high for several months, and may persist for years (7).

Pregnant women, children, and those with chronic hemolytic anemia such as sickle cell, thalassemia, and immunocompromised patients, are at increased risk of HPVB19 infection (8). The main transmission route of HPVB19 is respiratory secretions, particularly when the viral load is high (9). Since the prevalence of HPV-B19 is relatively high in the general population (10), The high volume of mixed plasma samples used in the preparation of plasma-derived factors causes some contamination in blood products (11). Since HPV- B19 is a non-enveloped virus, it's resistant to both physical and chemical inactivation techniques. Therefore, the possibility of its transmission through plasma-derived products used to treat hemophilia is relatively high $(12,13)$. A study on 38 serum samples from hemophilia patients reported that all of them were serologically positive for HPV-B19 infection (14). 
Another study that has investigated a patient who was received two lots of high-purity factor VIII concentrate reported that the patient became ill. The authors mentioned not screening the blood product for B19-DNA using the Nucleic acid Amplification Testing(NAT) as the main probable reason (15).

\section{Objectives}

Few studies have investigated the transmission of HPVB19 infection through single-donor blood components. However, some cases of anemia induced by transfusiontransmitted HPV- B19 have been reported (16-18). In this study, the seroprevalence of parvovirus B19 and the presence of B19 DNA are evaluated among blood donors in Golestan province by the ELISA and semi-nested PCR methods, respectively.

\section{Methods}

\subsection{Samples}

In this cross-sectional study, serum samples of 400 volunteer donors referred to blood transfusion centers in Golestan Province are analyzed. All samples were negative for HIV antibody (anti-HIV). Besides, the hepatitis B surface antigen (HBs Ag) and third-generation HCV antibody (anti$\mathrm{HCV}$ ) were selected randomly. A questionnaire was used to collect information on the age, gender, and marital status of participants. The study is approved by the local Research Ethics Committee of the High Institute for Research and Education in Transfusion Medicine.

\subsection{ELISA Method}

Anti-B19 (IgG and IgM) antibodies were detected by the ELISA (Enzyme-Linked Immunosorbent Assay) kit with commercial labels (Euroimmun, Germany). The ELISA methods were performed according to the instructions of the producer.

\subsection{Semi-Nested PCR}

Semi-nested PCR was used to detect B19 DNA. HPV-DNA extraction from serum was performed using the High Pure Nucleic Acid Extraction Kit (Roche, Mannheim, Germany). Then, the semi-nested PCR was used to detect PCR product using the following materials: $2 \mu \mathrm{L}$ of $10 \mathrm{X}$ PCR Buffer, 0.4 $\mu \mathrm{L}$ of $10 \mathrm{mM} \mathrm{dNTP}, 1.6 \mu \mathrm{L}$ of $25 \mathrm{mM} \mathrm{MgCl} 2,0.3 \mu \mathrm{L}$ of $5 \mathrm{unit} / \mu \mathrm{L}$ Taq polymerase, $10.3 \mu \mathrm{L}$ deionized water and $0.2 \mu \mathrm{L}$ of each $10 \mu \mathrm{m}$ forward and reverse primers. At the first stage, these primers were used: NS1 (5'-ATTGCATACAGACTTTGAGC-3') as the forward primer and NS2 (5'-CAGACTTTGAGCAGGTTATG3') as the reverse primer with 725 bp PCR product. Then
$5 \mu \mathrm{L}$ of extracted DNA was added to $15 \mu \mathrm{L}$ of PCR mixture. PCR amplification was performed for 30 cycles of denaturation for $1 \mathrm{~min}$ at $94^{\circ} \mathrm{C}$, following by annealing for 30 seconds at $58^{\circ} \mathrm{C}$, and extension for $1 \mathrm{~min}$ at $72^{\circ} \mathrm{C}$. For the second amplification, semi-nested PCR, $2 \mu \mathrm{L}$ of the reaction mixture was added to a new batch of $18 \mu \mathrm{L}$ of PCR mixture containing $10 \mu \mathrm{m}$ of each nested primers VP1 (5'AGCATCAGGAGCTATACTTCC-3') as the forward primer and NS2 (5'-CAGACTTTGAGCAGGTTATG-3') as a reversed primer with 717 bp PCR product $(19,20)$. PCR products were analyzed by agarose gel electrophoresis using DNA Green Viewer (Pars tous biotechnology, Iran), as dye. A negative serum sample and B19 DNA positive serum samples were used as negative and positive controls, respectively. For negative control samples, we used a serum that was negative for all blood-borne viruses, including HBV, HCV, HIV, HTIV, HAV, and HPV- B19 with the ELISA test.

\subsection{Statistical Analysis}

All data were analyzed using SPSS version 23. The ChiSquare Test was used to examine the relationship between two different factors. P values less than 0.05 were considered statistically significant.

\section{Results}

About $67 \%$ of blood donors were male, and $32.4 \%$ were female, who $67.6 \%$ of them were married. The mean age of participants was $35 \pm 10$ years; the youngest and oldest participants were 18 and 60 years old, respectively. Most of them (38.8\%) were in the age range of 26-35 years (Table 1). Of 400 blood donors who were tested for HPV- B19 antibodies (IgM and IgG), 242 (60.5\%; 95\% CI) were positive and 158 (39.5\%; 95\% CI) were negative for B19 IgG antibody. The minimum and maximum levels of B19 IgG antibodies were 0.25 and $126.80 \mathrm{IU} / \mathrm{mL}$, respectively. No positive case was recorded for the B19 IgM antibody.

Furthermore, no positive sample was detected for parvovirus B19 DNA by semi-nested PCR. The results of seminested PCR and agarose gel electrophoresis of the B19 genome are shown in Figure 1. Also, no significant association was found between age, gender, and marital status of blood donors and the seroprevalence of parvovirus B19 IgG antibody ( $\mathrm{P}>0.05)$ as shown in (Figure 2 and Figure 3 ).

\section{Discussion}

As a life-saving fluid, transfusion of human blood is of crucial importance to save the lives of many patients (e.g. those undergoing surgery). However, there are viruses that transmit through blood and blood products, even in cases 


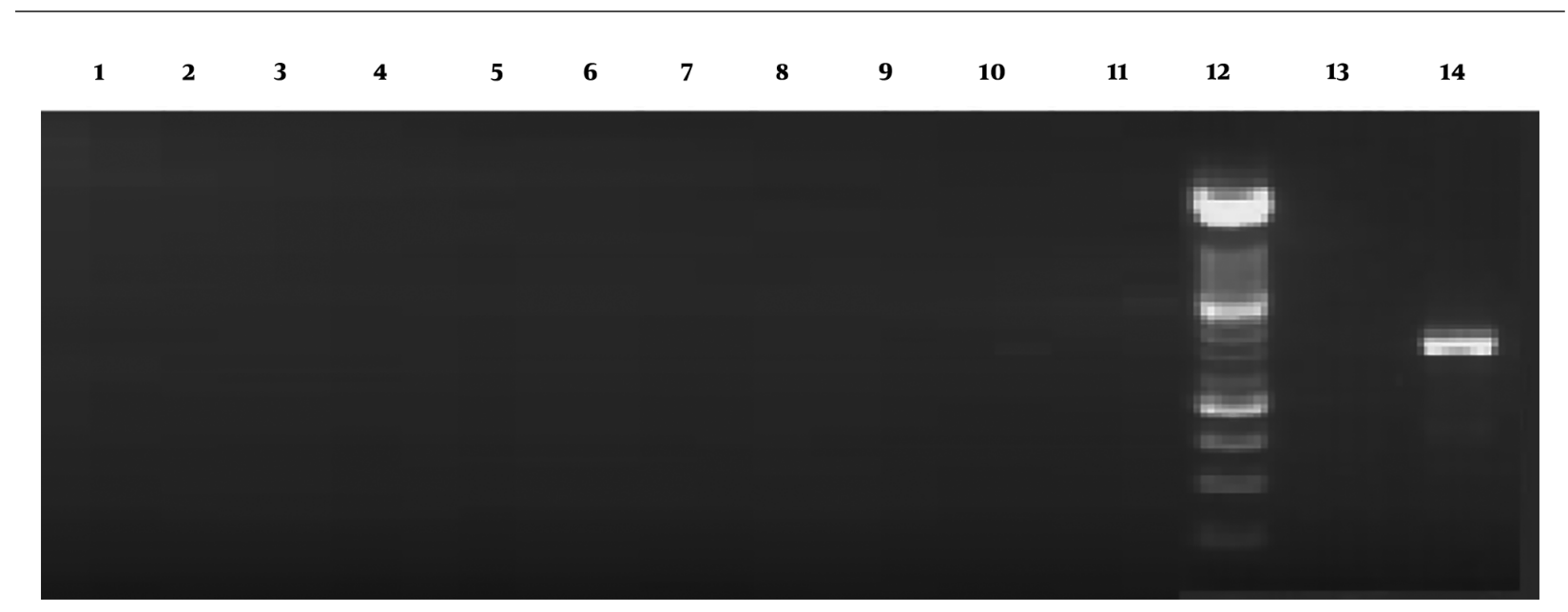

Figure 1. Agarose gel electrophoresis of Semi-nested PCR product of B19-DNA. Lanes 1-11, PCR product of blood donor serum samples. Lane 13, Negative control, Lanes 14 Positive control with 717 base pair length, Lane 12, DNA marker (100bp ladder (Roche@).

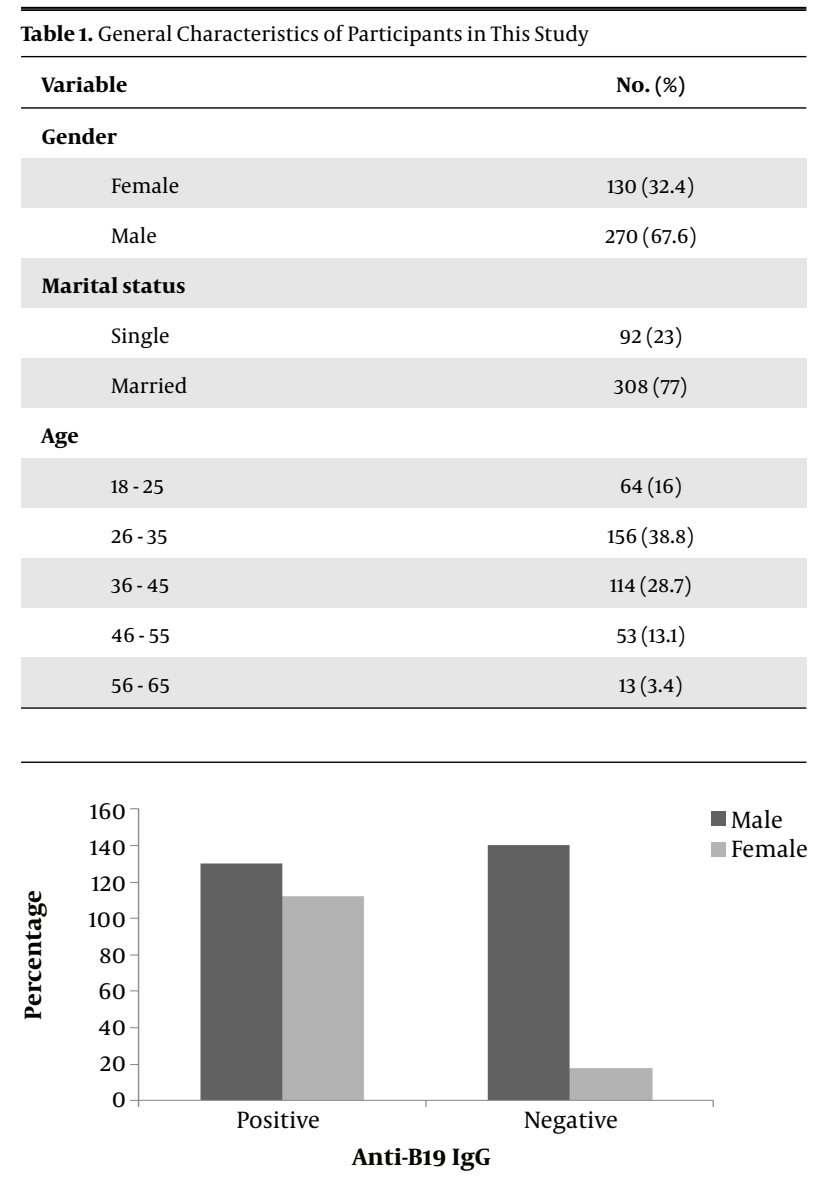

Figure 2. Comparison of the frequency of anti-B19 IgG antibody with sex that NAT and viral inactivation are performed. Previous studies have reported that due to the use of plasma pools containing HPV-B19 to produce batches of blood products, such as clotting factor concentrate, many of these packages are infected with HPV-B19 (21). Few studies have investigated the prevalence of B19 among blood donors in Iran. In the present study, $60.5 \%$ of samples had B19 IgG antibodies to human parvovirus B19. In a study on the sera of 730 blood donors in Tehran, the prevalence of the B19 IgG is reported as $46.3 \%$ (19). In another study performed from MayJune 2016 on 500 blood donors in Tehran, the prevalence of the B19 IgG is reported as $27.6 \%$ (22) (Table 2). These differences can be attributed to factors such as the sensitivity of the test as well as seasonal and geographical variations; It worth noting that the prevalence of parvovirus B19 increases during late winter and spring.

In a study conducted on blood donated by Korean donors, the prevalence of B19V DNA and anti-B19 IgG antibodies are reported as $0.0 \%$ and $60 \%$, respectively (Table 3) (26), which is consistent with the prevalence of IgG in the present study. The prevalence of IgG anti-B19 in Chile, China, Tunisia, Italy, Spain, and India is reported as 54.8\%, $55 \%, 43 \%, 79 \%, 64.7 \%$, and $27.96 \%$, respectively $(21,27-31)$.

There is evidence that suggests the prevalence of HPVB19-specific-IgG antibodies is directly associated with age. A study conducted in Tehran on children aged 5 - 9 years and adults aged 21-26 years has reported a prevalence of 79.3 and $86.6 \%$ for B19 IgG, respectively (10). Increasing the seroprevalence with age means that the proportion of people at risk to the virus decreases with increasing age, and this group is immune (10). In a study on hemophilia patients in Shiraz, a high percentage of patients was positive 


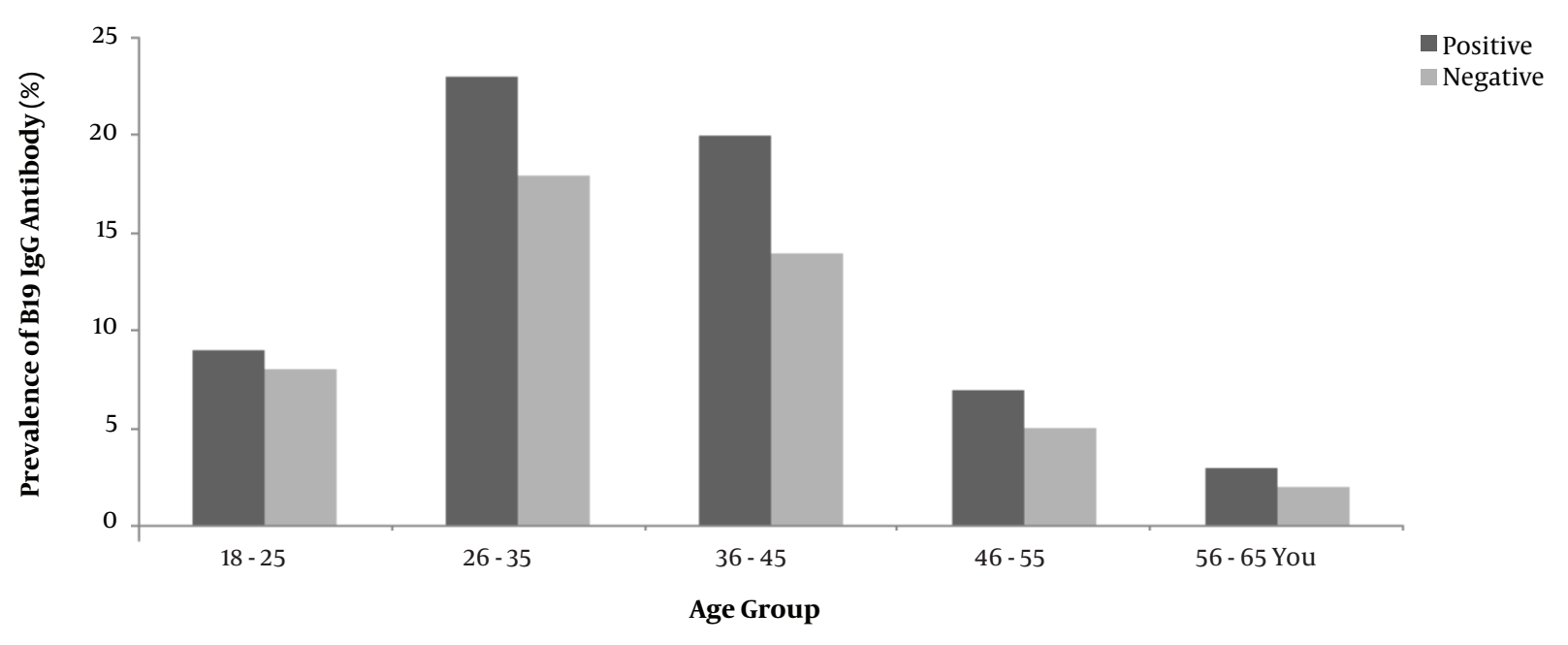

Figure 3. Comparison of IgG anti B19 antibody frequency in different age groups

\begin{tabular}{|c|c|c|c|c|c|c|c|}
\hline City & Year & Participants & No. & IgM & IgG & HPV DNA & Reference \\
\hline Shiraz & 2002 & Hemophilia & 180 & ND & $74 \%$ & $\mathrm{ND}^{\mathrm{a}}$ & (23) \\
\hline Azerbaijan & 2011 & Pregnant woman & 86 & ND & $75.6 \%$ & ND & (24) \\
\hline Urmia & 2014 & Kidney recipients & 9 & ND & $69.2 \%$ & ND & (25) \\
\hline Tehran & 2008 & $5-25$ year old age & 1500 & $0.0 \%$ & $86.6 \%$ & $0.0 \%$ & (10) \\
\hline Tehran & 2008 & Blood donor & 730 & $0.5 \%$ & $46.3 \%$ & $0.0 \%$ & (19) \\
\hline Tehran & 2018 & Blood donor & 500 & $2.6 \%$ & $27.6 \%$ & $1.2 \%$ & (22) \\
\hline Golestan & 2019 & Blood donor & 400 & $0.0 \%$ & $60.5 \%$ & $0.0 \%$ & Present study \\
\hline
\end{tabular}

${ }^{\mathrm{a}}$ ND: No Data.

\begin{tabular}{llllllll}
\hline Table 3. Global Prevalence of $\mathrm{HPV}^{\mathrm{a}}$ & & & & & \\
\hline Country & Year & Participants & No. & IgM & IgG & HPV DNA & Reference \\
\hline Korea & 2008 & Blood donors & 928 & ND & $60.1 \%$ & $(26)$ \\
Chile & 2003 & Blood donors & 400 & ND & $54.8 \%$ & ND & ND \\
China & 2006 & Blood donors & 184 & ND & $55.43 \%$ & ND & ND \\
India & 2008 & Blood donors & 540 & ND & $27.96 \%$ & $(28)$ & \\
\hline
\end{tabular}

${ }^{\mathrm{a}}$ ND: No Data

for anti- B19 IgG compared to the control group (74\% vs. $56 \%)(32)$.

In another study performed on pregnant women in West Azerbaijan in 2011, a prevalence of $75.6 \%$ is reported (23). Also, the prevalence of HPV- B19 (69.2\%) is reported to be high among kidney recipients in Urmia (Iran)(24).

In this study, no IgM positive sample was found. In a study performed on sera of 730 blood donors in Tehran, the prevalence of IgM is reported as 0.5\%. Doyle et al. reported a seroprevalence of $1 \%$ among American blood donors (33), whereas Munoza reported a prevalence of $0 \%$ among Spanish blood donors (31). Also, in the present study, all sera samples were negative, as determined by sensitive and specific semi-nested PCR. The sensitivity of the NAT method significantly influences the prevalence of B19 viremia in blood and plasma of donors, so that it may range from $0.003 \%$ to $0.88 \%$ (25). Low levels of HPV- B19 DNA (i.e., 10 to $103 \mathrm{IU} / \mathrm{mL}$ ) with anti-HPV-B19 IgG may persist for three to 
five years in immunocompetent blood donors (25). Many of the samples negative for B19 DNA are positive for antiB19 IgG antibodies, which indicates that the majority of donors have been exposed to the virus and, therefore, have developed the antibody response. Currently, most developed countries do not implement necessary measures to prevent the transmission of B19 through blood and blood products because the dominant view is that blood components with low levels of B19 DNA do not transmit B19 infection (34, 35).

In conclusion, the present study demonstrated a high IgG prevalence among donors in Golestan Province. Also, none of the samples was positive for B19 DNA, which indicates the low risk of B19 transmission through blood transfusion. The presence of anti-B19 IgG in the blood of the donors or recipients leads to neutralization of the virus, which in turn prevents the infection. Donors with persistent IgG anti- HPV- B19 might be considered as "HPVB19 -safe" for single-donor blood components. Regardless of the high prevalence of anti-B19 IgG in Iranian blood donors, transfusion-transmitted human HPV- B19 is considered as an unresolved problem, particularly for those with high sensitivity such as pregnant women, immunedeficient patients, and patients with hematological problems. Hence, implementing preventive measures with a special focus on these groups would be useful.

\section{Acknowledgments}

The authors would like to thank the Blood Transfusion Research Center, High Institute for Research and Education in Transfusion Medicine for supporting this study.

\section{Footnotes}

Authors' Contribution: Ameneh Elikaei suggested and financed the study, Ameneh Karimnia collected the data, and Zohreh Sharifi analyzed the samples and supervised the analysis process.

Conflict of Interests: The authors declare no conflict of interest.

Ethical Approval: Ethics approval was obtained from the local Research Ethics Committee of the High Institute for Research and Education in Transfusion Medicine.

Funding/Support: The High Institute of Research in Transfusion Medicine and Alzahra University financially supported the study.

\section{References}

1. Cossart YE, Cant B, Field AM, Widdows D. Parvovirus-like particles in human sera. The Lancet. 1975;305(7898):72-3. doi: 10.1016/s01406736(75)91074-0.
2. Heegaard ED, Brown KE. Human parvovirus B19. Clin Microbiol Rev. 2002;15(3):485-505. doi: 10.1128/cmr.15.3.485-505.2002. [PubMed: 12097253]. [PubMed Central: PMC118081].

3. Shade RO, Blundell MC, Cotmore SF, Tattersall P, Astell CR. Nucleotide sequence and genome organization of human parvovirus B19 isolated from the serum of a child during aplastic crisis. J Virol. 1986;58(3):921-36. doi:10.1128/JVI.58.3.921-936.1986. [PubMed:3701931]. [PubMed Central: PMC253001].

4. Ozawa K, Ayub J, Kajigaya S, Shimada T, Young N. The gene encoding the nonstructural protein of B19 (human) parvovirus may be lethal in transfected cells. J Virol. 1988;62(8):2884-9. doi: 10.1128/JVI.62.8.28842889.1988. [PubMed: 2969055]. [PubMed Central: PMC253725].

5. Young NS, Brown KE. Parvovirus B19. NEngl JMed. 2004;350(6):586-97. doi:10.1056/NEJMra030840. [PubMed:14762186].

6. Dodd RY. B19: benign or not? Transfusion. 2011;51(9):1878-9. doi: 10.1111/j.1537-2995.2011.03274.x. [PubMed: 21896028].

7. Corcoran A, Doyle S. Advances in the biology, diagnosis and hostpathogen interactions of parvovirus B19. J Med Microbiol. 2004;53(Pt 6):459-75. doi: 10.1099/jmm.0.05485-0. [PubMed: 15150324].

8. Iheanacho MC, Akanmu SA, Nwogoh B. Seroprevalence of parvovirus BI9 antibody in blood donors and sickle cell disease patients at Lagos university teaching hospital(LUTH): a comparative study.African JClin Exp Microbiol. 2013;15(1). doi: 10.4314/ajcem.v15i1.3.

9. Brown KE. The expanding range of parvoviruses which infect humans. Rev Med Virol. 2010;20(4):231-44. doi: 10.1002/rmv.648. [PubMed: 20586082].

10. Salimi V, Gouya MM, Esteghamati A, Safaie A, Heshmat R, Saadatmand $Z$, et al. Seroepidemiology of human Parvovirus B19 in 5-25 year old age people in Iran. Iran J Public Health. 2008:19-25.

11. Schmidt I, Blumel J, Seitz H, Willkommen H, Lower J. Parvovirus B19 DNA in plasma pools and plasma derivatives. Vox Sang. 2001;81(4):22835. doi: 10.1046/j.1423-0410.2001.00120.x. [PubMed: 11903998].

12. Azzi A, Morfini M, Mannucci P. The transfusion-associated transmission of parvovirus B19. Transfus Med Rev. 1999;13(3):194-204. doi: 10.1016/s0887-7963(99)80033-9.

13. Santagostino E, Mannucci PM, Gringeri A, Azzi A, Morfini M, Musso $\mathrm{R}$, et al. Transmission of parvovirus B19 by coagulation factor concentrates exposed to 100 degrees $C$ heat after lyophilization. Transfusion. 1997;37(5):517-22. doi: 10.1046/j.1537-2995.1997.37597293884.x. [PubMed: 9149778].

14. Zakrzewska K, Azzi A, De Biasi E, Radossi P, De Santis R, Davoli PG, et al. Persistence of parvovirus B19 DNA in synovium of patients with haemophilic arthritis. J Med Virol. 2001;65(2):402-7. doi: 10.1002/jmv.2048. [PubMed: 11536251].

15. Wu CG, Mason B, Jong J, Erdman D, McKernan L, Oakley M, et al. Parvovirus B19 transmission by a high-purity factor VIII concentrate. Transfusion. 2005;45(6):1003-10. doi: 10.1111/j.1537-2995.2005.04387.x. [PubMed: 15935000].

16. Zanella A, Rossi F, Cesana C, Foresti A, Nador F, Binda AS, et al. Transfusion-transmitted human parvovirus B19 infection in a thalassemic patient. Transfusion. 1995;35(9):769-72. doi: 10.1046/j.15372995.1995.35996029163.x. [PubMed: 7570939].

17. Yoto Y, Kudoh T, Haseyama K, Suzuki N, Oda T, Katoh T, et al. Incidence of human parvovirus B19 DNA detection in blood donors. BrJ Haematol. 1995;91(4):1017-8. doi: 10.1111/j.1365-2141.1995.tb05427.x. [PubMed: 8547113].

18. Cohen BJ, Beard S, Knowles WA, Ellis JS, Joske D, Goldman JM, et al. Chronic anemia due to parvovirus B19 infection in a bone marrow transplant patient after platelet transfusion. Transfusion. 1997;37(9):947-52. doi: 10.1046/j.1537-2995.1997.37997454023.x. [PubMed: 9308643]. 
19. Mahmoudi F, Mahmoudian SM, Sharifi Z, Hosseini SM. [Prevalence of parvovirus B19 in blood donors tested by ELISA and PCR]. The scientific journal of iranian blood transfusion organization (khoon). 2008;5(1):4752. Persian.

20. Takahashi Y, Murai C, Shibata S, Munakata Y, Ishii T, Ishii K, et al. Human parvovirus B19 as a causative agent for rheumatoid arthritis. Proc Natl Acad Sci U S A. 1998;95(14):8227-32. doi: 10.1073/pnas.95.14.8227. [PubMed: 9653169]. [PubMed Central: PMC20958].

21. Kumar S, Gupta RM, Sen S, Sarkar RS, Philip J, Kotwal A, et al. Seroprevalence of human parvovirus B19 in healthy blood donors. Med J Armed Forces India. 2013;69(3):268-72. doi: 10.1016/j.mjafi.2012.11.009. [PubMed: 24600121]. [PubMed Central: PMC3862746].

22. Zadsar M, Aghakhani A, Banifazl M, Kazemimanesh M, Tabatabaei Yazdi SM, Mamishi S, et al. Seroprevalence, molecular epidemiology and quantitation of parvovirus B19 DNA levels in Iranian blood donors. J Med Virol. 2018;90(8):1318-22. doi: 10.1002/jmv.25195. [PubMed: 29663448].

23. Khameneh ZR, Hanifian H, Barzegari R, Sepehrvand N. Human parvovirus B19 in Iranian pregnant women: a serologic survey. Indian J Pathol Microbiol. 2014;57(3):442-4. doi:10.4103/0377-4929.138748. [PubMed: 25118740].

24. Khameneh ZR, Sepehrvand N, Sohrabi V, Ghasemzadeh N. The seroprevalence of Parvovirus B19 among kidney transplant recipients: a single-center study. Saudi J Kidney Dis Transpl. 2014;25(1):16-21. doi: 10.4103/1319-2442.124465. [PubMed: 24434377].

25. Yu MY, Alter HJ, Virata-Theimer ML, Geng Y, Ma L, Schechterly CA, et al. Parvovirus B19 infection transmitted by transfusion of red blood cells confirmed by molecular analysis of linked donor and recipient samples. Transfusion. 2010;50(8):1712-21. doi: 10.1111/j.1537-2995.2010.02591.x. [PubMed: 20158689]. [PubMed Central: PMC5547753].

26. Oh DJ, Lee YL, Kang JW, Kwon SY, Cho NS. Investigation of the prevalence of human parvovirus B19 DNA in Korean plasmapheresis donors. Korean J Lab Med. 2010;30(1):58-64. doi: 10.3343/kjlm.2010.30.1.58. [PubMed: 20197724].

27. Gaggero A, Rivera J, Calquin E, Larranaga CE, Leon O, Diaz P, et al. [Sero- prevalence of IgG antibodies against parvovirus B19 among blood donors from Santiago, Chile]. Rev Med Chil. 2007;135(4):443-8. doi: 10.4067/s0034-98872007000400005. [PubMed: 17554452].

28. Wei Q, Li Y, Wang JW, Wang H, Qu JG, Hung T. Prevalence of anti-human parvovirus B19 IgG antibody among blood donors in Jilin province. Zhonghua Shi Yan He Lin Chuang Bing Du Xue Za Zhi. 2006;20(2):60.

29. Regaya F, Khelifa R, Zouari R, Kchir M, Karoui M, Essid R. Research on Parvovirus B19 infections and chronic articular manifestations in a Tunisian hospital [Research on Parvovirus B19 infections and chronic articular manifestations in a Tunisian hospital].Arch Inst PasteurTunis. 2003;80(1-4):9-15. French.

30. Manaresi E, Gallinella G, Morselli Labate AM, Zucchelli P, Zaccarelli D, Ambretti S, et al. Seroprevalence of IgG against conformational and linear capsid antigens of parvovirus B19 in Italian blood donors. Epidemiol Infect. 2004;132(5):857-62. doi:10.1017/s0950268804002389. [PubMed: 15473148]. [PubMed Central: PMC2870172].

31. Munoz S, Alonso MA, Fernandez MJ, Munoz JL, Garcia-Rodriguez JA Seroprevalence versus parvovirus B19 in blood donors. Enferm Infecc Microbiol Clin. 1998;16(4):161-2.

32. Mahmoudian SM, Hamkar R, Nabi FM. High prevalence of parvovirus B19 IgG antibody among hemophilia patients in center for special diseases, Shiraz, Iran. Iran J Public Health. 2005;34(1):51-4.

33. Doyle S, Kerr S, O'Keeffe G, O'Carroll D, Daly P, Kilty C. Detection of parvovirus B19 IgM by antibody capture enzyme immunoassay: receiver operating characteristic analysis. Journal of Virological Methods. 2000;90(2):143-52. doi: 10.1016/s0166-0934(00)00227-5.

34. Thomas I, Di Giambattista M, Gerard C, Mathys E, Hougardy V, Latour $\mathrm{B}$, et al. Prevalence of human erythrovirus B19 DNA in healthy Belgian blood donors and correlation with specific antibodies against structural and non-structural viral proteins. Vox Sang. 2003;84(4):300-7. doi: 10.1046/j.1423-0410.2003.00299.x. [PubMed: 12757504].

35. Candotti D, Etiz N, Parsyan A, Allain JP. Identification and characterization of persistent human erythrovirus infection in blood donor samples. J Virol. 2004;78(22):12169-78. doi: 10.1128/JVI.78.22.12169 12178.2004. [PubMed: 15507603]. [PubMed Central: PMC525065]. 